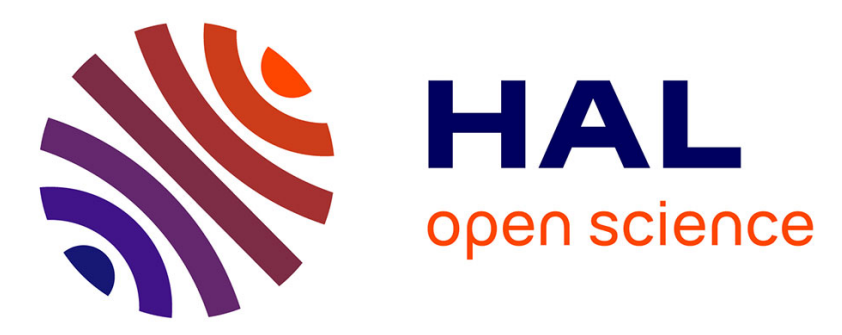

\title{
Numerical modelling of the seismic behaviour of a 7-story building: NEES benchmark
}

\author{
Stéphane Grange, Panagiotis Kotronis, Jacky Mazars
}

\section{To cite this version:}

Stéphane Grange, Panagiotis Kotronis, Jacky Mazars. Numerical modelling of the seismic behaviour of a 7-story building: NEES benchmark. Materials and structures, 2009, 42 (10), pp.1433-1442. 10.1617/s11527-008-9462-y . hal-01007147

\section{HAL Id: hal-01007147 \\ https://hal.science/hal-01007147}

Submitted on 14 Jan 2020

HAL is a multi-disciplinary open access archive for the deposit and dissemination of scientific research documents, whether they are published or not. The documents may come from teaching and research institutions in France or abroad, or from public or private research centers.
L'archive ouverte pluridisciplinaire HAL, est destinée au dépôt et à la diffusion de documents scientifiques de niveau recherche, publiés ou non, émanant des établissements d'enseignement et de recherche français ou étrangers, des laboratoires publics ou privés. 


\title{
Numerical modelling of the seismic behaviour of a 7- story building: NEES benchmark
}

\author{
Stéphane Grange, Panagiotis Kotronis, Jacky Mazars \\ Grenoble Universités, Labor. Sols Solides Structures-Risques (3S-R), C.N.R.S. \\ Domaine Universitaire BP 53, 38041 Grenoble cedex 9, France
}

25 December, 2007

\begin{abstract}
The American NEES Consortium Inc (NEESinc) has performed a seismic research project around an uniaxial shaking table test on a structure representing a full-scale vertical slice of a 7-story reinforced concrete wall building. This paper deals with the numerical strategy adopted in the laboratory 3S-R for a "blind" simulation of the non linear behaviour of the specimen. Multifiber Timoshenko beam elements are used for the finite element mesh of the reinforced concrete walls. Constitutive models are based on damage mechanics for concrete and plasticity for steel. It is shown that the proposed modelling strategy describes accurately the global behaviour of the structure (even though the prediction is "blind"). Then, comparison with the experimental results helps to identify the deficiencies of the original numerical model and to propose remedies in order to improve its performance. Based on the results obtained it appears possible to use this approach to investigate numerically the behaviour of a wider variety of configurations that is practically impossible to study experimentally.
\end{abstract}

Keywords: shaking table; Timoshenko beam; multifiber ; concrete; building

\section{Introduction}

A 7-story building has been recently tested by the University of California at San Diego (UCSD), the Portland Cement Association (PCA) of Skokie, IL. and the NEES Consortium Inc (NEESinc) (NEES7story website, 2006), (NEES7story report, 2006). The tests were part of a seismic research project around uniaxial experiments of increasing intensity on a test structure representing a full-scale vertical slice of a reinforced concrete wall building fixed on the new NEES Large HighPerformance Outdoor Shake Table. The test structure is composed of 2 main perpendicular walls: the web wall and the flange wall linked with slabs (figure 1). A pre-cast column needed to limit torsional behaviour and gravity columns to support the slabs are also present. The building slice, which was designed using a displacement-based and capacity approach for a site in Los Angeles, resulted in design lateral forces that are significantly smaller than those currently specified in building codes used in the United States. 
This article presents the numerical work performed in the laboratory Sols Solides Structures - Risques (3S-R) in Grenoble (France) in order to participate to the benchmark NEES/UCSD. The benchmark was performed between October 2005 and January 2006. The aim of the study presented hereafter is to reproduce numerically the non linear behaviour of the full-scale vertical slice of the 7-story reinforced concrete walls building. Only the direction Y of loading is considered (parallel to the web wall). Four input motions at different intensities denoted EQ1, EQ2, EQ3 and EQ4 have been used with increasing maximum acceleration going from $0.15 \mathrm{~g}$ to $0.85 \mathrm{~g}$. Simulations are performed with FedeasLab, a finite element Matlab toolbox developed by Pr. F. Filippou and his co-workers in UC Berkeley (Filippou and Constandines, 2004). The building is modelled using Timoshenko multifiber beam elements ((Kotronis and Mazars, 2005) and (Mazars et al., 2006)). Constitutive material laws are based on damage mechanics to describe cracking of concrete (La Borderie, 1991) and on plasticity for steel ((Filippou et al., 1983), (Menegoto and Pinto, 1973)). The Timoshenko multifiber beam element and the damage mechanic law have been introduced into FedeasLab by the 3S-R group.

At the first part of the paper, comparisons with the experimental response are "blind" (Grange et al., 2007), meaning that the experimental results were not known in advance. It is shown that the proposed modelling strategy describes accurately the global behaviour of the structure and qualitatively the distribution of damage at the base of the specimen. In the second part of the paper a comparison with the experimental results helps to identify the deficiencies of the original numerical model and to propose remedies to improve its performance.

We present hereafter in detail the experimental loading sequences, the mesh, the material parameters and the response of the numerical model compared with the experimental one.

\section{Input accelerations and spectra}

Four input motions (denoted EQ1, EQ2, EQ3 and EQ4) have been used for the experiments with increasing maximum acceleration going from $0.15 \mathrm{~g}$ to $0.85 \mathrm{~g}$. The first two records EQ1 and EQ2 come from the longitudinal and transverse components of the 1971 San Fernando earthquake, EQ3 comes from the longitudinal component of the 1994 Northridge earthquake and EQ4 corresponds to the 1994 Northridge earthquake Sylmar record as reproduced by the NEES-UCSD shaking table (figure 2). 

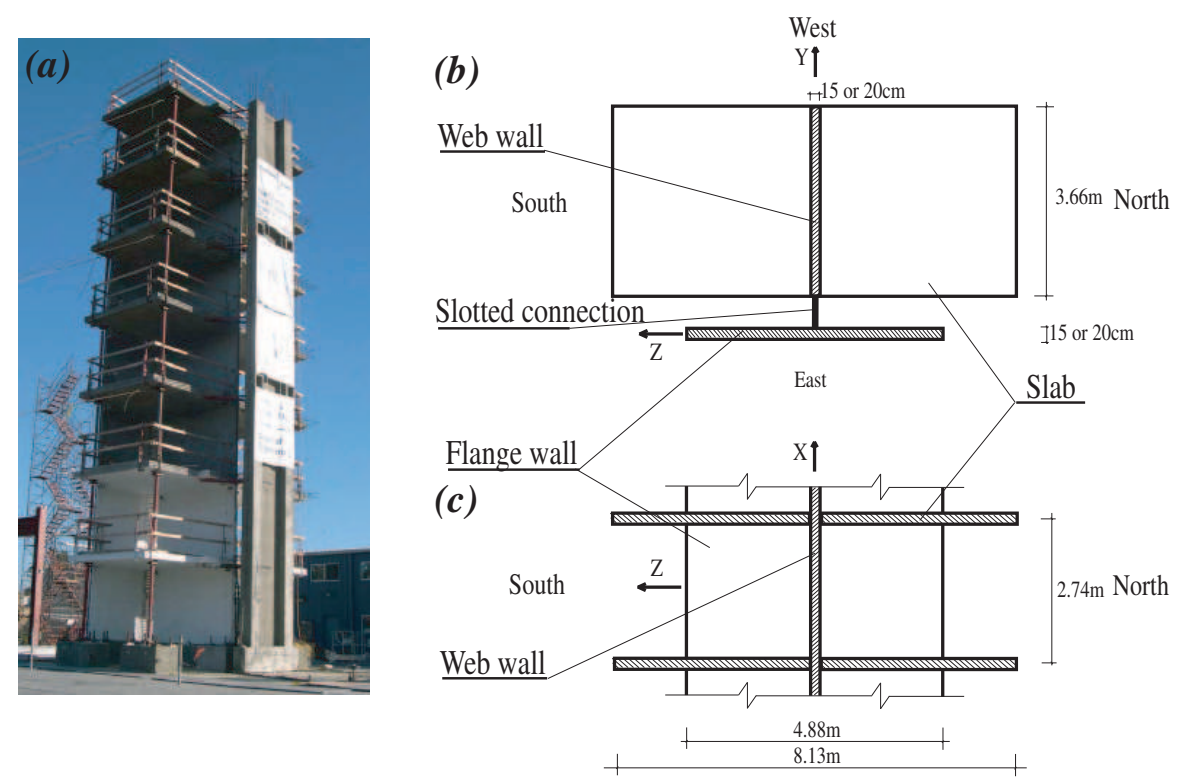

Figure 1. (a) North West view of the test structure and geometrical data of the test structure: (b) Plan view, (c) Elevation view.

EQ1 and EQ2 are quite long and have a high bandwidth of accelerations. Their peak ground accelerations are respectively $0.15 \mathrm{~g}$ and $0.26 \mathrm{~g}$. EQ3 and EQ4 are very close in terms of frequency content and have a thin bandwidth of high accelerations. Their peak ground accelerations are respectively $0.33 \mathrm{~g}$ and $0.85 \mathrm{~g}$. The frequency content of EQ4 signal is rich around $3.22 \mathrm{~Hz}(0.31 \mathrm{~s})$ which is not so close to the natural frequency of the experimental structure (measured equal to $1.82 \mathrm{~Hz}(0.55 \mathrm{~s})$ ) (figure 3). Nevertheless, EQ3 and EQ4 response spectra present another peak at $10 \mathrm{~Hz}(0.1 \mathrm{~s})$ close to the second bending natural mode calculated numerically.

\section{Numerical model of the structure}

\subsection{Spatial Discretization}

A good comprehension of the role of each structural element is important in order to choose the appropriate finite element mesh of the structure. The building is made of a web wall and a flange wall connected by slotted connections. They constitute the main skeleton of the structure supporting the seven slabs. Reinforcement steel bars have a common density for this kind of structure in USA. More particularly, 8 bars of $8 \mathrm{~mm}$ diameter are used at both extremities of the web wall 


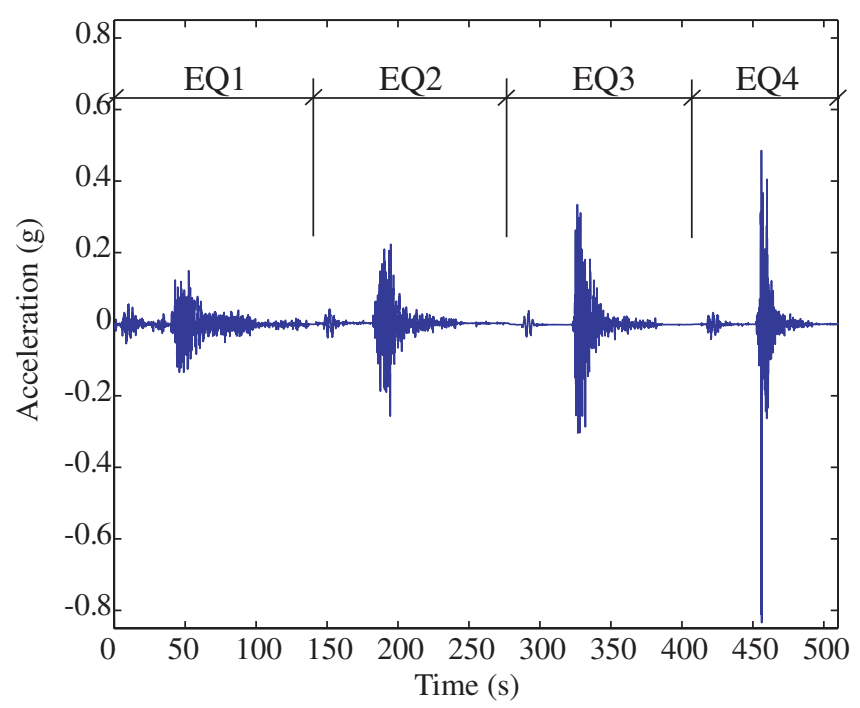

Figure 2. Ground motions EQ1, EQ2, EQ3 and EQ4.

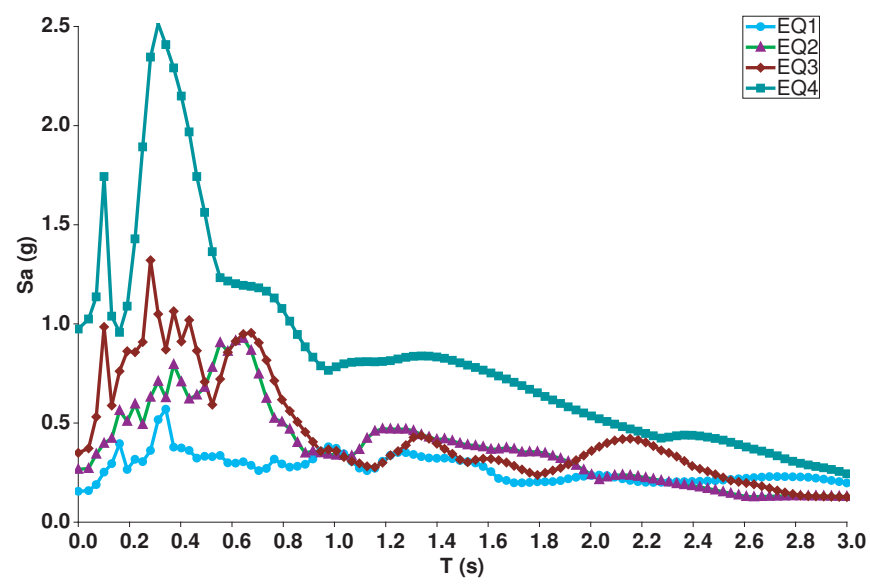

Figure 3. Acceleration response spectra - 5\% damping. 

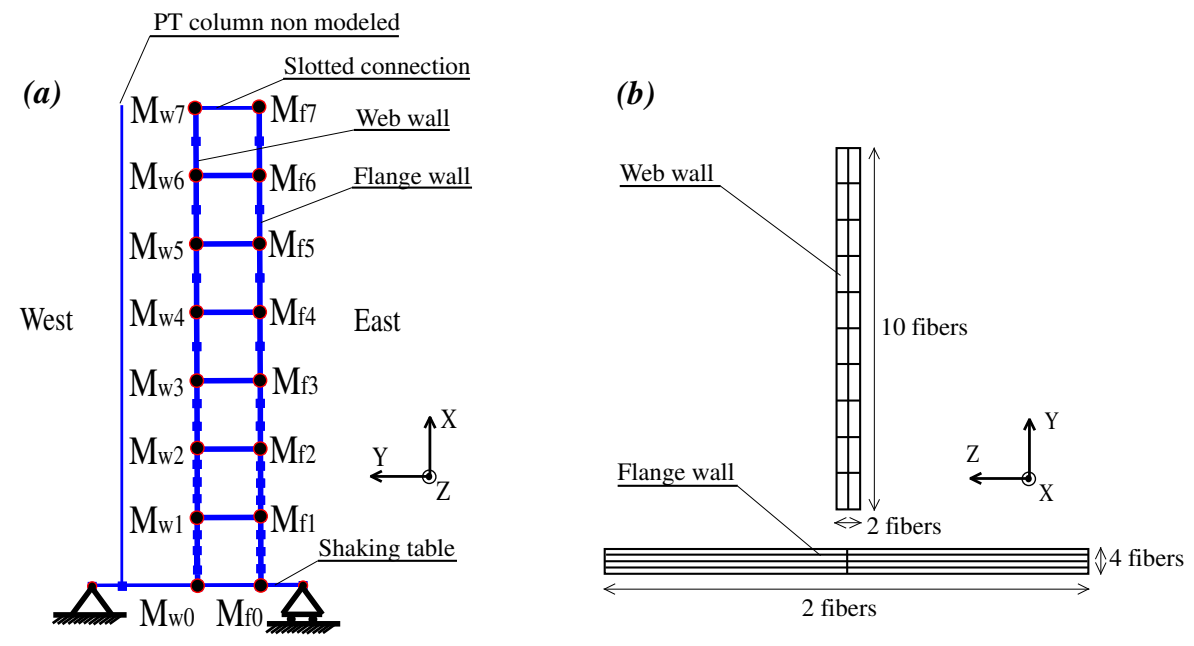

Figure 4. (a) Finite element mesh and concentrated masses and (b) fibers in a given section.

and 13 bars of $6 \mathrm{~mm}$ diameter distributed equally in its middle. Gravity columns permit to support the weight of the slabs and they are positioned at their extremities. The dynamic excitation is applied only towards the Y direction (in the plane of the web wall, see figure 4). To avoid any 3D effects and particular any torsional mode, pre-cast segmental piers (PT columns) and bracing are used.

Because the dynamic excitation are unidirectional, the gravity columns, the pre-cast segmental pier and the bracing system are not taken into account into the numerical model presented hereafter. Figure 4 (a) gives a representation of the finite element discretization. The web wall and the flange wall are decomposed into 19 multifiber Timoshenko beam elements (4 elements for levels 1 and 2, 3 elements for level 3 and 2 elements for levels 5, 6 and 7). The slotted connections between the two walls are simulated using linear horizontal truss elements. Thus, only normal forces are transmitted. Four linear Bernoulli beam elements are used to reproduce the shaking table.

\subsection{Distribution of Masses}

Concentrated masses are considered at each floor taking into account the mass of the corresponding slab and the upper and lower part of the wall. They are presented in table I, table II and figure 4(a). The total mass of the structure is about $M_{t o t}=182000 \mathrm{~kg}$. 
Table I. Masses and rotational inertia for nodes in the web wall.

\begin{tabular}{lcc}
\hline Node & Masses $M_{w}(k g)$ & Rotational inertia $I_{w z}\left(k g . m^{2}\right)$ \\
\hline$w_{0}$ & 11780 & 20080 \\
$w_{1}$ & 18470 & 23100 \\
$w_{2}$ & 17910 & 22000 \\
$w_{3}$ & 17910 & 22000 \\
$w_{4}$ & 17910 & 22000 \\
$w_{5}$ & 17910 & 22000 \\
$w_{6}$ & 17910 & 22000 \\
$w_{7}$ & 16200 & 22000 \\
\hline
\end{tabular}

Table II. Masses and rotational inertia for nodes in the flange wall.

\begin{tabular}{lcc}
\hline Node & Masses $M_{f}(\mathrm{~kg})$ & Rotational inertia $I_{f z}\left(\mathrm{~kg} \cdot \mathrm{m}^{2}\right)$ \\
\hline$f_{0}$ & 15500 & 5499 \\
$f_{1}$ & 5376 & 3582 \\
$f_{2}$ & 4576 & 3071 \\
$f_{3}$ & 4576 & 3071 \\
$f_{4}$ & 4576 & 3071 \\
$f_{5}$ & 4576 & 3071 \\
$f_{6}$ & 4576 & 3071 \\
$f_{7}$ & 2126 & 1535 \\
\hline
\end{tabular}

\subsection{Constitutive LaWs}

Constitutive model for concrete under cyclic loading ought to take into account some observed phenomena such as decrease in material stiffness due to cracking, stiffness recovery which occurs at crack closure and inelastic strains concomitant to damage. To simulate this behaviour we use a damage model with two scalars variables, one in compression and one in tension (La Borderie, 1991). Unilateral effect and stiffness recovery (damage deactivation) are also included. Inelastic strains are taken into account thanks to an isotropic tensor (figure 5). The total strain is given by: 


$$
\left\{\begin{array}{l}
\epsilon=\epsilon^{\mathbf{e}}+\epsilon^{\text {in }} \\
\epsilon^{\mathbf{e}}=\frac{\langle\sigma\rangle_{+}}{E\left(1-D_{1}\right)}+\frac{\langle\sigma\rangle_{-}}{E\left(1-D_{2}\right)}+\frac{\nu}{E}(\sigma-\operatorname{Tr}(\sigma) \mathbf{I}) \\
\epsilon^{\text {in }}=\frac{\beta_{1} D_{1}}{E\left(1-D_{1}\right)} \frac{\partial f(\sigma)}{\partial \sigma}+\frac{\beta_{2} D_{2}}{E\left(1-D_{2}\right)} \mathbf{I}
\end{array}\right.
$$

where

$$
\left\{\begin{array}{l}
\operatorname{Tr}(\sigma) \in[0,+\infty) \rightarrow \frac{\partial f(\sigma)}{\partial \sigma}=\mathbf{I} \\
\operatorname{Tr}(\sigma) \in\left[-\sigma_{f}, 0\right] \rightarrow \frac{\partial f(\sigma)}{\partial \sigma}=\left(1-\frac{\operatorname{Tr}(\sigma)}{\sigma_{f}}\right) \mathbf{I} \\
\operatorname{Tr}(\sigma) \in\left(-\infty,-\sigma_{f}\right] \rightarrow \frac{\partial f(\sigma)}{\partial \sigma}=0 . \mathbf{I}
\end{array}\right.
$$

with $\epsilon^{\mathbf{e}}$ the elastic strains, $\epsilon^{\mathbf{i n}}$ the inelastic strains and $\sigma$ the stress tensor. I denotes the unit tensor, $\operatorname{Tr}(\sigma)=\sigma_{i j}, f$ is the crack closure function and $\sigma_{f}$ the crack closure stress. $\langle.\rangle_{+}$denotes the positive and $\langle.\rangle_{\text {_ }}$ the negative part of the tensor. $E$ is the initial Young's modulus and $\nu$ the Poisson ratio. $D_{1}$ and $D_{2}$ are respectively the damage variables for tension and compression, $\beta_{1}$ and $\beta_{2}$ are material constants. Damage criteria are expressed as $f_{i}=Y_{i}-Z_{i}(i=1$ for tension or 2 for compression, $Y_{i}$ is the associated force to the damage variable $Z_{i}$ and $Z_{i}$ a threshold dependent on the hardening variables). The evolution laws for the damage variables $Z_{i}$ are written as:

$$
D_{i}=1-\frac{1}{1+\left[A_{i}\left(Y_{i}-Y_{0 i}\right)\right]^{B_{i}}}
$$

where $Y_{0 i}$ is the initial elastic threshold $\left(Y_{0 i}=Z_{i}\left(D_{i}=0\right)\right.$ and $A_{i}, B_{i}$ material constants. For the calculations presented hereafter the uniaxial version of the damage model is used (shear is considered linear). Figure 5 gives the stress-strain response of the model for an uniaxial tensioncompression.

A modified version of the classical Menegoto-Pinto model (Filippou et al., 1983), (Menegoto and Pinto, 1973) with an isotropic hardening is used for steel.

The material data parameters of concrete and steel are fitted using the values provided in the contest rules. To simplify the problem only one type of concrete (concrete specimen number "c3", (NEES7story website, 2006), (NEES7story report, 2006)) and steel are adopted. An ultimate compressive stress of $f_{c}=37.4 \mathrm{MPa}(=5.43 \mathrm{ksi})$ for a compressive strain of $\epsilon_{c u}=0.00259$ is chosen and the Young modulus is taken equal to $E=24.46 G P a(=3549 \mathrm{ksi})$. In tension, the ultimate stress is $f_{t}=3 \mathrm{MPa}(=0.43 \mathrm{ksi})$ according to the empirical French rule $\left(f_{t}=0.6+0.06 f_{c}\right)$ (BAEL91, 2000). The ultimate stress and yield stress for steel are taken equal to $f_{s u}=710 \mathrm{MPa}(=103 \mathrm{ksi})$ and $f_{y}=450 \mathrm{MPa}(=65.3 \mathrm{ksi})$ respectively. The corresponding ultimate 


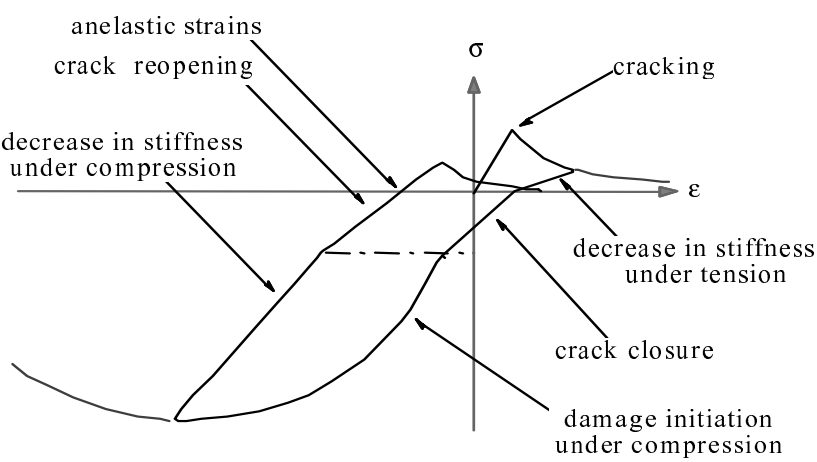

Figure 5. Cyclic response of the La Borderie Model.

Table III. Material data for the constitutive laws.

\begin{tabular}{cccc}
\hline \multicolumn{2}{c}{ concrete parameters } & \multicolumn{2}{c}{ steel parameters } \\
\hline$E$ & $24.46 G \mathrm{~Pa}$ & $E$ & $200 \mathrm{GPa}$ \\
$\nu$ & 0.2 & $f_{y}$ & $450 \mathrm{MPa}$ \\
$Y_{01}$ & $335 \mathrm{~Pa}$ & $f_{s u}$ & $710 \mathrm{MPa}$ \\
$Y_{02}$ & $0.05 \mathrm{MPa}$ & $\epsilon_{s h}$ & 0.0060 \\
$A_{1}$ & $4000 \mathrm{MPa} a^{-1}$ & $\epsilon_{s u}$ & 0.10 \\
$A_{2}$ & $4.01 \mathrm{MPa}^{-1}$ & & \\
$B_{1}$ & 1.2 & & \\
$B_{2}$ & 1.335 & & \\
$\beta_{1}$ & $1 \mathrm{MPa}$ & & \\
$\beta_{2}$ & $-40 \mathrm{MPa}$ & & \\
$\sigma_{f}$ & $3.5 \mathrm{MPa}$ & & \\
\hline
\end{tabular}

strain and yield strain are $\epsilon_{s u}=0.10$, and $\epsilon_{s h}=0.0060$. Theses values lead to the material data parameters presented in table III.

\subsection{Multifiber SECTiOnS}

The multifiber elements composing the web wall are divided into 20 concrete fibres, whereas those of the flange wall are divided into 8 concrete fibres (figure 4 (b)). The number and the position of the fibres representing the longitudinal reinforcement steels are the same with those in the real section (see details of the sections in the contest rules (NEES7story website, 2006), (NEES7story report, 2006)). 


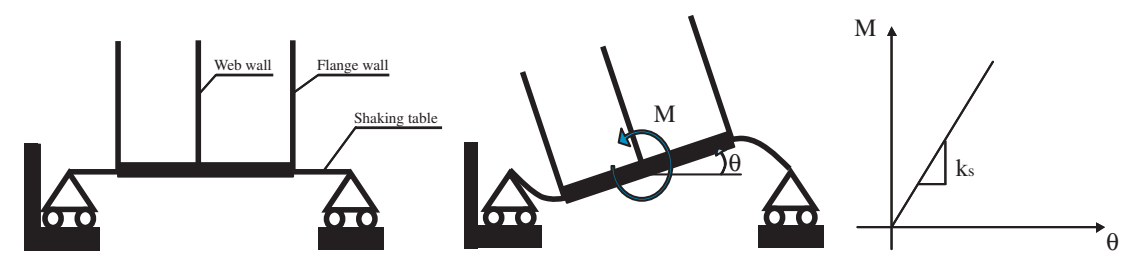

Figure 6. Tuning of the rotational stiffness of the shaking table.

\subsection{StiffNess of THE SHAKING TABLE}

The shaking table is modelled using 4 linear elastic Bernoulli beam elements. The total length of the beams equals the length of the shaking table. Two of them are positioned below the structure having very high values of axial and bending stiffness. The bending stiffness of the two other beams is tuned according to the rotational stiffness provided by the official contest rules (figure 6).

\subsection{Numerical STRATEGY}

The classical Newmark time integration scheme is used for the calculations assuming a constant variation of the acceleration $\left(\gamma=\frac{1}{2}\right.$ and $\beta=\frac{1}{4}$ ). The secant Newton-Raphson strategy is chosen and the Rayleigh damping coefficients have been adjusted to ensure a value on $2 \%$ on the first and the fourth mode. P- $\delta$ effects are neglected and for computational reasons the 4 dynamic motions (EQ1, EQ2, EQ3, EQ4) have been launched independently (the structure is considered undamaged at the beginning of each loading).

\section{Experimental versus "blind" prediction numerical results}

\subsection{Modal Analysis}

The modal analysis of the numerical model provides the natural frequencies and the modal shapes in table IV and figure 7 . The first mode (bending) corresponds to a low frequency $1.74 \mathrm{~Hz}$. This is to be compared with the only experimental mode measured after a white noise test $(1.82 \mathrm{~Hz})$.

The second mode is actually a coupled bending-pumping mode. This deformed shape is due to eccentricity of the structure on the shaking table, which generated no-symmetrical displacements. 
Table IV. Frequency and modes of the structure.

\begin{tabular}{lcc}
\hline Modes & frequency $\mathrm{Hz}$ & shape \\
\hline 1 & 1.74 & bending 0.25T \\
2 & 7.94 & pumping(+bending) \\
3 & 10.33 & bending 0.5T \\
\hline
\end{tabular}
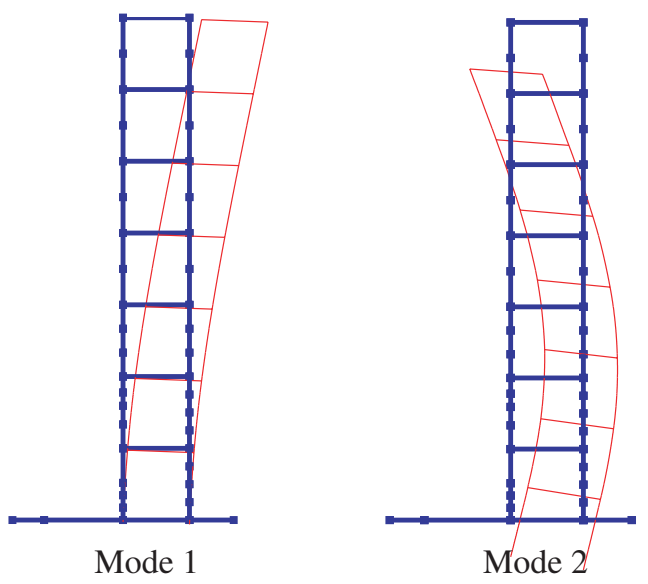

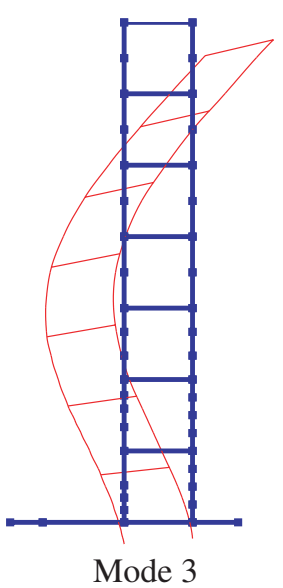

Mode 3

Figure \%. Modal shapes.

\subsection{NON LINEAR TRANSIENT DYNAMIC ANALYSIS}

The maximum predicted and measured lateral displacements, floor accelerations, and inter-story drift ratios, for each level and for the 4 motions (EQ1, EQ2, EQ3 and EQ4) are presented in figures 8, 9 and 10.

The moment at the stage $i\left(M_{i}\right)$ as well as the story shear force $V_{i}$ are evaluated based on the accelerations of each level (equations 4 and $5)$ :

$$
\begin{gathered}
M_{i}=\sum_{k=i+1}^{7}\left(M_{w i}+M_{f i}\right) \ddot{u}_{Y k}\left(X_{k}-X_{i}\right) \quad i \in[0 ; 6] \\
V_{i}=\sum_{k=i+1}^{7}\left(M_{w i}+M_{f i}\right) \ddot{u}_{Y k} \quad i \in[0 ; 6]
\end{gathered}
$$

where $\ddot{u}_{Y k}$ is the horizontal acceleration according to $Y$ axis of node $k$ and $X_{k}$ is the height (according to $X$ axis) of node $k$. 

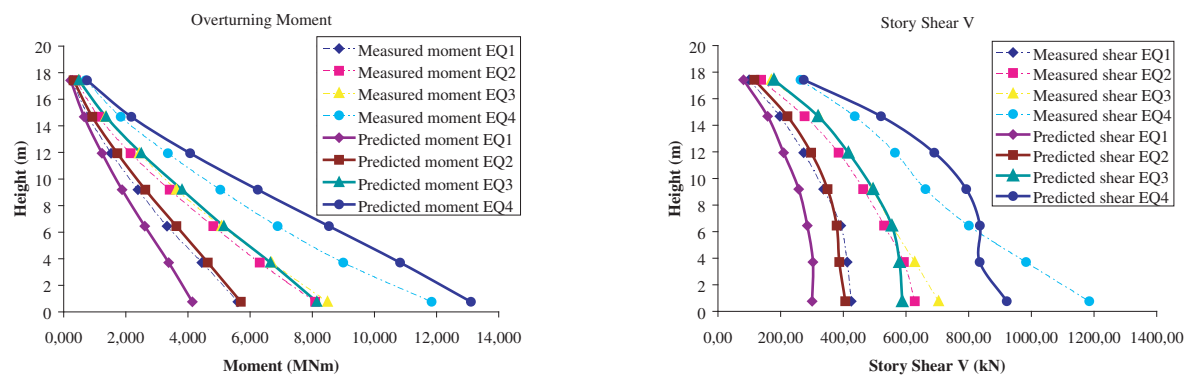

Figure 8. Maximum overturning moments and story shear forces at different levels of the structure for the 4 sequences, comparisons between experimental (dotted lines) and "blind" prediction numerical results (continuous lines).
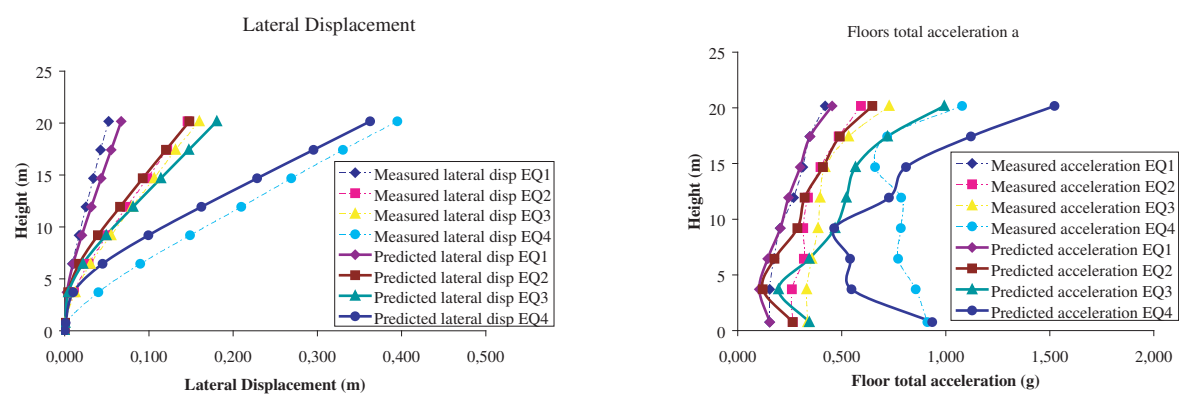

Figure 9. Maximum lateral displacements and accelerations at different levels of the structure for the 4 sequences, comparisons between experimental (dotted lines) and "blind" prediction numerical results (continuous lines).

The inter-story drift ratio for the story between the nodes $i$ and $i+1$ $\left(I D_{i, i+1}\right)$ is calculated according to equation 6 :

$$
I D_{i, i+1}=\frac{u_{Y i+1}-u_{Y i}}{X_{i+1}-X_{i}} \quad i \in[0 ; 6]
$$

where $u_{Y k}$ is the horizontal displacement according to $Y$ axis of node $k$ and $X_{k}$ is the height (according to $X$ axis) of node $k$.

The "blind" predicted response is generally close to the experimental behaviour. Overturning moments and story shear forces are slightly underestimated for the EQ1 and EQ2 sequences and slightly overestimated for sequence EQ4 (figure 8). Concerning the lateral displacements (figure 9), they are overestimated for sequence EQ1 and underestimated for sequence EQ4. In other words, the numerical structure is softer than the experimental one at the beginning of the tests, but is stiffer for the sequence EQ4. This difference comes certainly from the fact that the four dynamic motions have been launched independently in the numerical model. This is a point that needs to be improved in the future. 


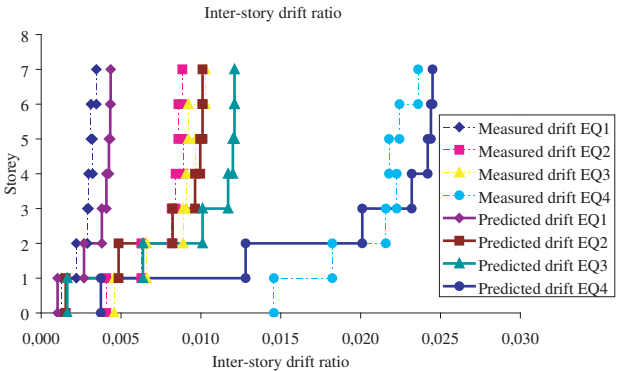

Figure 10. Maximum interstory drift ratios in the structure for the 4 sequences, comparisons between experimental (dotted lines) and "blind" prediction numerical results (continuous lines).
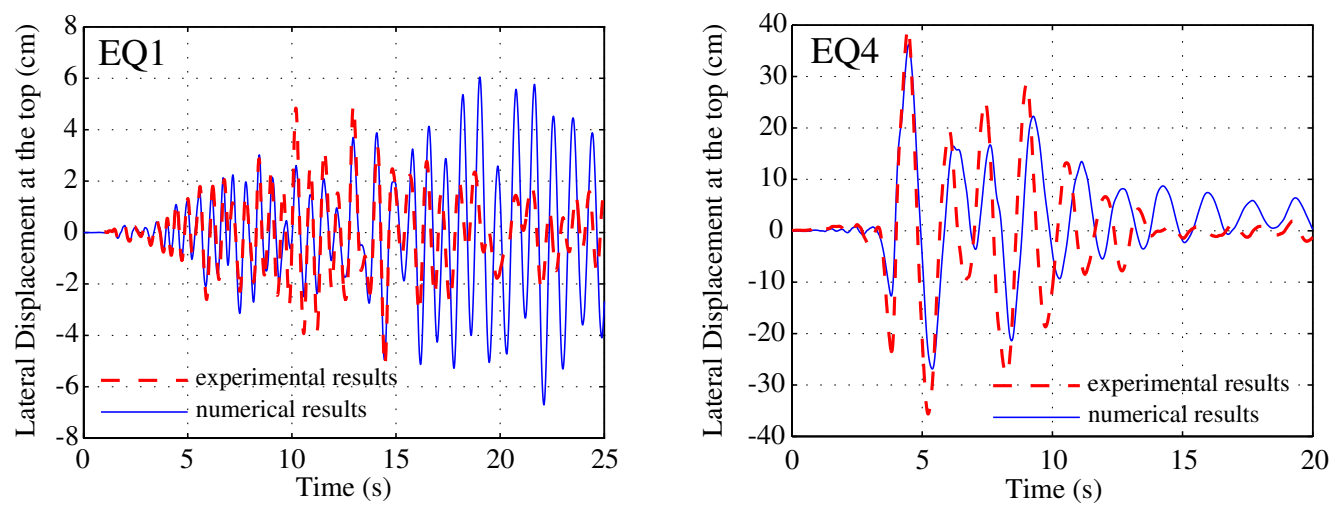

Figure 11. Lateral displacements at the top versus time for EQ1 and EQ4. Experimental (dashed lines) and "blind" prediction numerical results (continuous lines).

Accelerations at different levels of the structure for the different sequences are close to the experimental results (figure 9) except for the sequence EQ4 where maximum accelerations at the middle of the structure are lower. Interstory drift ratio given in figure 10 show clearly where the non-linearities are concentrated (high values of strains and damage).

The time histories of the calculated and experimental lateral displacements at the top of the structure for the EQ1 and the EQ4 sequences are presented in figure 11. For the EQ1 sequence, simulation satisfactorily predicts the behaviour until the first 10 seconds. After that, the lateral displacement is overestimated. For the EQ4 sequence, the maximum displacement is correctly reproduced. Nevertheless, there is a shift between the curves at the final steps of the loading. 

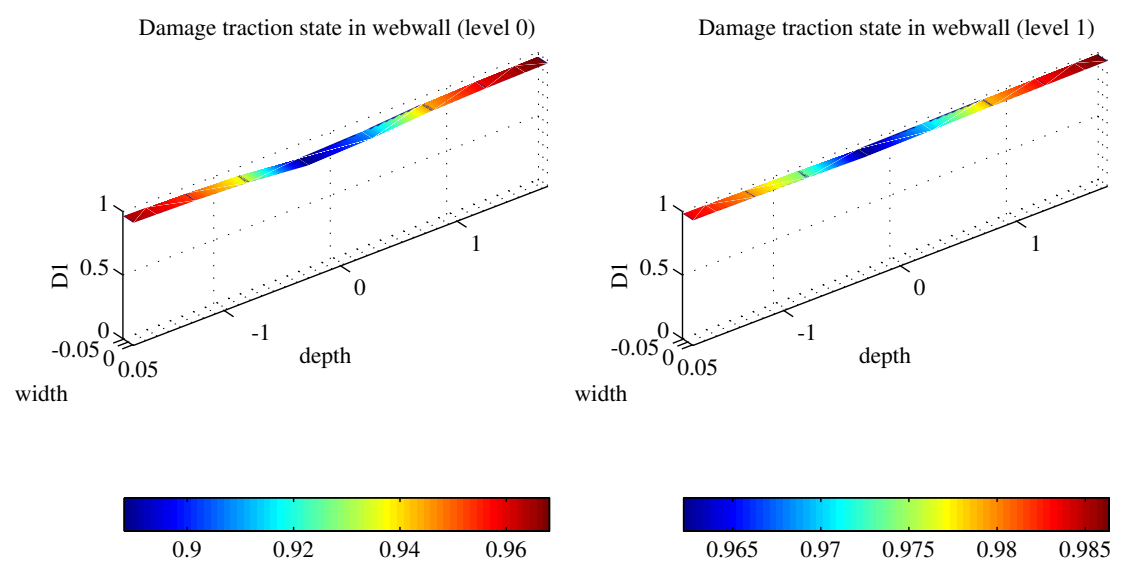

Figure 12. Initial numerical model: State of damage in concrete due to tension for the initial numerical model at levels 0 and 1 (EQ1).

\section{Post-tests improvements of the numerical model}

Two major improvements have been introduced to the original numerical model once the experimental results known. The first concerns the description of the continuity of the steel bars at the junction of levels 0 and 1 and the second a better "tuning" of the material and damping data. They are presented in detail hereafter.

\subsection{Considering the CONTinuity of Steels at the junction OF LEVELS 0 AND 1}

Figure 12 shows the tension damage variable $D_{1}$ in the web wall section. This damage variable varies normally between 0 (non damaged section) and 1.0 (completely damaged section). By filtering its value between 0.95 and 1.0, one can have an image of the distribution of the apparent cracks in the structure.

In the original numerical model, reinforcement bars were considered at the junction between levels 0 and 1 (where the width of the section is reduced from $20 \mathrm{~cm}(8 \mathrm{in})$ to $15 \mathrm{~cm}(6 \mathrm{in}))$. This proved to be a mistake, leading to an unrealistic distribution of damage that was found to be concentrated all over the first two floors (figure 12). By adding reinforcement bars at the junction, the link between the 2 levels is made stronger.

Figure 13 shows the tension damage variable $D_{1}$ in the web wall section considering the new more realistic distribution of reinforcement bars. Damage is now found to be concentrated at the base of the web wall (level 0) and only at the extremities of the wall at level 1. Comparison with the actual position of cracks at the end of the experiment 

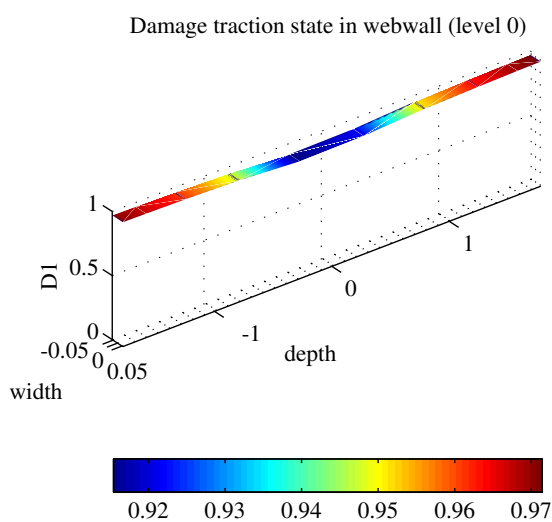

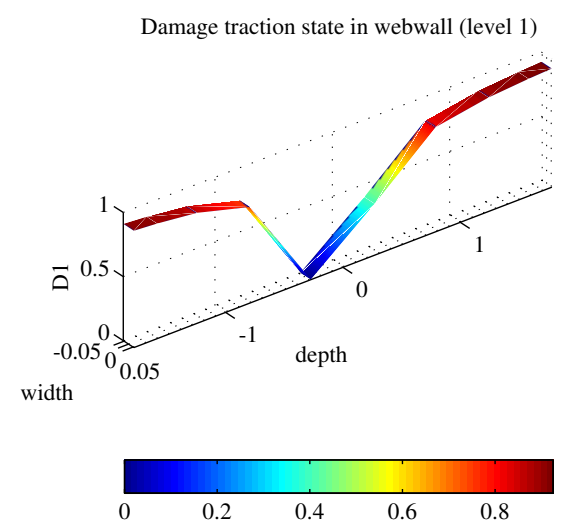

Figure 13. Post-tests improvements - Numerical model: State of damage in concrete due to tension for the modified numerical model at levels 0 and 1 considering continuity of steels (EQ1).

shows that the model is now more capable to reproduce the trend observed experimentally.

\subsection{Considering NeW Material And DAmping DAta}

According to right picture of figure 11, it is clear that the frequency of the numerical model is lower than the experimental one. In order to improve the numerical response the following material parameters have been changed: The concrete ultimate stress in tension $f_{t}$ is not known precisely. A new value is chosen equal to $f_{t}=4 M P a(=0.57 \mathrm{ksi})$. The steel yield stress $f_{y}$ can be increased according to the values given in the contest rules. The new value is chosen equal to $f_{y}=500 \mathrm{MPa}$ $(=72.5 \mathrm{ksi})$. The last point concerns the coefficients of the Rayleigh damping. The new damping ratio applied to the first and the fourth modes is taken equal to $2.2 \%$.

Comparison between the new numerical results and the experimental ones for the EQ1 and EQ4 sequences in terms of the lateral displacements at the top of the structure is given in figure 14 (continuity of steels is also taken into account). The numerical curves are now in phase with the experimental ones and the peaks are correctly reproduced.

\subsection{INFLUENCE OF THE FIRST MODE ON THE BEHAVIOR OF THE STRUCTURE}

The behaviour of the structure in terms of moments and displacements is primarily guided by the first mode. This can be identified by proceeding to the modal decomposition of the moments according to the Karhunen-Loéve method (Gutierrez and Zaldivar, 2000). Figure 15 (a) 

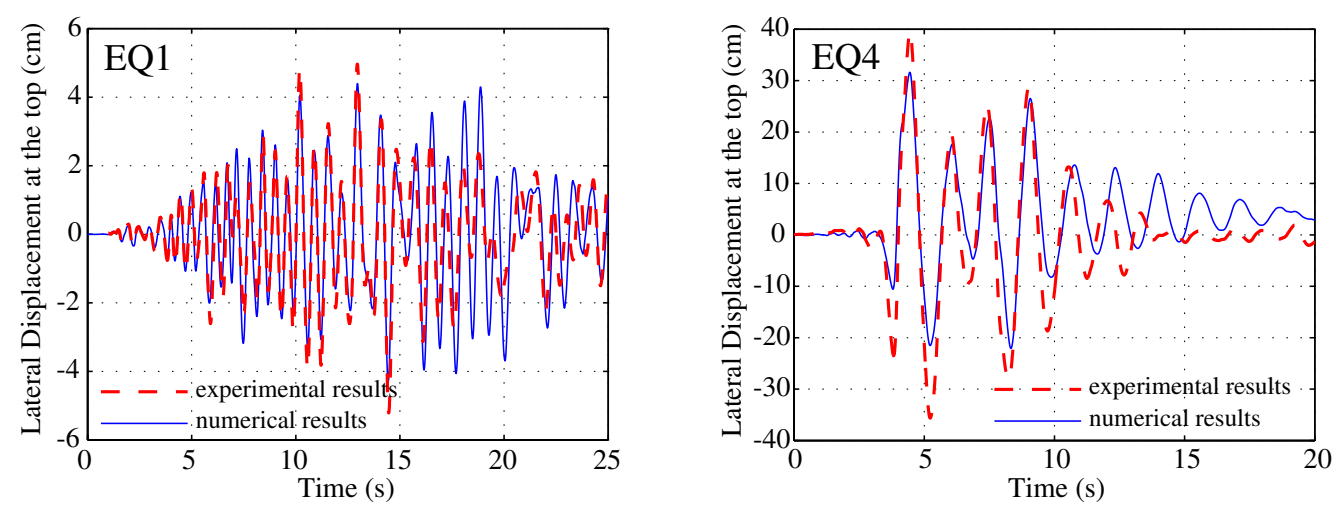

Figure 14. Post-tests improvements: Lateral displacements at the top versus time for EQ1 and EQ4. Experimental (dashed lines) and numerical results (continuous lines) considering new material and damping data and continuity of steels
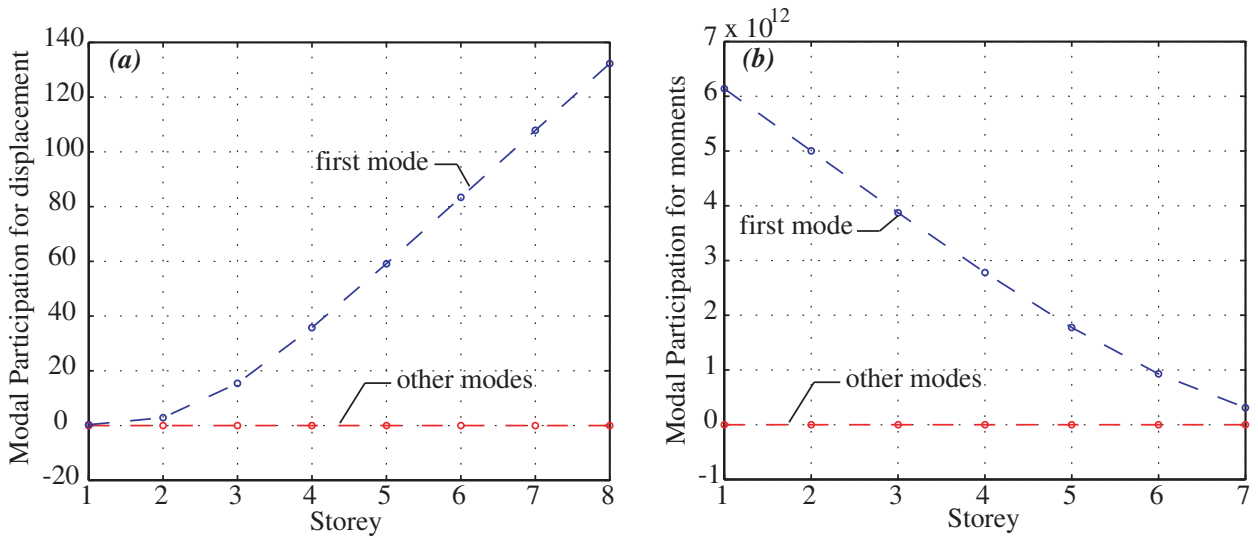

Figure 15. Post-tests improvements - Numerical model: Static modal shape of the displacements (a) and moments (b)

and (b) show the static modal shape of the modal displacements (projection of the displacements on the modal space) and modal moments (projection of the moments on the modal space). It is obvious that the first mode contributes significantly to the moments developed in the structure and displacements. Although the results presented in figure 15 are only for EQ4, the same trend is found for EQ1, EQ2 and EQ3 sequences. 


\section{Conclusion and way forward}

As demonstrated throughout this work, a modelling strategy based on Timoshenko multifiber beam elements and constitutive laws within the framework of damage mechanics for concrete and plasticity for steel is able to reproduce with good approximation the global response of the 7-story NEES building and qualitatively the distribution of damage ("blind" calculations). Moreover, this simplified approach helps to reduce computational costs (one loading sequence takes only a couple of hours with Matlab). Once the experimental results were available, improvements were obtained to the initial model by reproducing correctly the continuity of the reinforcement bars and by adjusting some material and damping parameters. We would like at this point to emphasize again the importance of reproducing accurately the actual length of the reinforcement bars in the finite element mesh. Otherwise, local results (i.e. damage variables) may be misleading...Finally, the application of the Karhunen-Loéve method (Gutierrez and Zaldivar, 2000) is a very usuful tool to get an insight into the behaviour of the structure. For the NEES specimen, it is shown that the behaviour is mainly guided by the first mode.

It appears now possible to use this kind of modelling strategy to investigate numerically the behaviour of a wider variety of configurations that is practically impossible to study experimentally. For example, the influence of Soil Structure Interaction (SSI) on the behaviour of the NEES structure for different types of soils is studied in (Grange et al., 2007). It is done by introducing a recently developed macro-element (Grange et al., 2008) between the multifiber Timoshenko beams modelling the structure and the shaking table. The first results show, as expected, a reduction of the internal forces and an increase of the displacements at the top of the structure but also, a shifting in the excitation of the modes. Such numerical tools are necessary for the practical engineer in order to reproduce satisfactorily the non linear behaviour of a structure and the interaction with its boundary conditions.

\section{Acknowledgements}

The authors are grateful for the financial support of the European Contract LESSLOSS, Risk Mitigation for Earthquakes and Landslides of the Sixth Framework Program (Project No.: GOCE-CT-2003-505488). They would like to thank the organizers of the seven-story building-slice earthquake "blind" prediction contest for their financial support that made possible for the 3S-R group to participate to the NEES/UCSD 
Workshop and Seminar "Analytical Model of Reinforced Concrete Walls" held in San Diego the 15th and 16th of December 2006.

\section{References}

BAEL91. Règles techniques de conception et de calcul des ouvrages et constructions en béton armé suivant la méthode des états-limites. Eyrolles, Paris, France, 2000.

Filippou, F. C., E. P. Popov, and V, V. Bertero. Effects of bond deterioration on hysteretic behaviour of reinforced concrete joints. Technical report EERC-83/19, Earthquake Engrg. Res. Ctr. Univerity of California, Berkeley, 1983.

Filippou, F. C., M. Constandines. FedeasLab Getting Started Guide And Simulations Examples. Dpt of civil and env. Engng. UC Berkeley, 2004.

Grange, S., P. Kotronis, and J. Mazars. A macro-element for a circular foundation to simulate 3D soil-structure interaction. International Journal for Numerical and Analytical Methods in Geomechanics, (early view), 2008.

Grange, S., P. Kotronis, and J. Mazars. Extensive validation of the SSI macro element using experimental and numerical results. Deliverable [D8-2], European Contract LESSLOSS, Project No.: GOCE-CT-2003-505488, Risk Mitigation for Earthquakes and Landslides, Sixth Framework Programme, 2007. http://hal.archives-ouvertes.fr/hal-00138210

Gutiérrez, E., and J. M. Zaldivar. The application of Karhunen-Love, or principal component analysis method, to study the non-linear seismic response of structures. Earthquake Engng Struct. Dyn, 29:1261-1286, 2000.

Kotronis, P., and J. Mazars. Simplified modelling strategies to simulate the dynamic behaviour of r/c walls. Journal of Earthquake Engineering, 9(2):285-306, 2005.

La Borderie, C. Phénomènes unilatéraux dans un matériau endommageable: modélisation et application l'analyse des structures en béton. $\mathrm{PhD}$ thesis, Université Paris 6, 1991.

Mazars, J., P. Kotronis, F. Ragueneau, and G. Casaux. Using multifiber beams to account for shear and torsion. applications to concrete structural elements. Computer Methods in Applied Mechanics and Engineering, 195(52):7264-7281, 2006.

Menegoto, M., P. Pinto. Method of analysis of cyclically loaded reinforced concrete plane frames including changes in geometry and non-elastic behaviour of elements under combined normal force and bending. IABSE Symposium on resistance and ultimate deformability of structures acted on by well-defined repeated loads, final report, Lisbon, 328p, 1973.

NEES7story website. NEES/UCSD seven-story building-slice earthquake blind prediction contest. http://nees.ucsd.edu/7Story.html 2006.

NEES7story report. NEES/UCSD Workshop and Seminar on Analytical Modeling of Reinforced Concrete Walls for Earthquake Resistance. (Report), UC San Diego, USA-California, December 15-16, 2006. 
Article2.tex; 30/09/2008; $10: 31 ;$ p.18 